\title{
Urinary iodine and thyroid determinants in pregnancy: a follow up study in Sri Lanka
}

Eric De Zoysa ${ }^{1}$, Manjula Hettiarachchi ${ }^{2^{*}}$ and Chandrani Liyanage ${ }^{3}$

\begin{abstract}
Background: lodine deficiency and thyroid dysfunction during pregnancy is associated with number of adverse outcomes that includes mental and physical disabilities creating a huge human and economic burden in later life. Several indicators are used to assess the iodine status of a population: thyroid size by palpation and/or by ultrasonography, urinary iodine excretion and the blood thyroid hormone profile.

Methods: This prospective study was designed to assess the iodine nutrition during the course of pregnancy with reference to urine iodine concentration $(\mathrm{UIC})$ and thyroid determinants among 425 pregnant women from Galle district, Sri Lanka. UIC was estimated in all three trimesters and thyroid functions were assessed in first and third trimesters.
\end{abstract}

Results: Median (inter-quartile range IQR) UIC was 170.9 (100.0-261.10) $\mu \mathrm{g} / \mathrm{L}, 123.80$ (73.50-189.50) $\mu \mathrm{g} / \mathrm{L}$ and 105.95 $(67.00-153.50) \mu \mathrm{g} / \mathrm{L}$ in the first, second and third trimesters respectively $(p<0.001)$. Median thyroid stimulating hormone (TSH) level in the first trimester was $1.30(0.80-1.80) \mu \mathrm{lU} / \mathrm{mL}$. This value significantly increased $(p<0.001)$ to 1. $60(1.20-2.10) \mu \mathrm{lU} / \mathrm{mL}$ at the $3^{\text {rd }}$ trimester even though it was maintained within the reference range $(0.3-5.2 \mu \mathrm{lU} / \mathrm{mL})$. In the assessment of thyroid gland, $67(16.0 \%)$ women had palpable or visible goitres and $55(13.1 \%)$ had a goitre that was palpable but not visible. The median thyroid volume of the sample was $5.16 \mathrm{~mL}(4.30 ; 6.10 \mathrm{~mL})$ as measured by ultra sound (US) scanning. In multiple regression analysis after controlling for other independent variables (anthropometric, demographic and biochemical parameters); initial body mass index (BMI), goitre size, thyroid volume and parity had significant correlations with the third trimester urinary iodine levels. The thyroid volume accounted for $4.5 \%$ of the urinary iodine variation.

Conclusions: Even though iodine status was progressively worsening with the advancement of pregnancy and iodized salt consumption has not met with the increasing demand for iodine, it was not reflected in the serum TSH level. Therefore, it is worthwhile to assess the long term effects of rising TSH levels and inadequate iodine nutrition during pregnancy on the offspring to prevent even mild iodine deficiency.

Keywords: Urinary iodine, lodine status in pregnancy, Thyroid stimulating hormone, Thyroid volume, Goitre in pregnancy

\section{Background}

Maternal iodine deficiency and thyroid dysfunction during pregnancy is associated with number of adverse outcomes. During the first two trimesters of pregnancy, the foetus is entirely dependent on the maternal thyroid hormone supply because the foetal thyroid does not develop until 13-15weeks of gestation [1]. As the foetus progresses into the third trimester, it develops the ability to produce its own thyroid hormones but still dependent on maternal

\footnotetext{
* Correspondence: manjulah@med.ruh.ac.lk

${ }^{2}$ Nuclear Medicine Unit, Faculty of Medicine, University of Ruhuna, P.O. Box

70, Galle, Sri Lanka

Full list of author information is available at the end of the article
}

iodine for hormone synthesis [2]. Thyroid hormone is required for normal neuronal migration, myelination, and synaptic transmission and plasticity during fetal and early postnatal life and hypothyroxinemia during these critical periods causes irreversible brain damage with mental retardation and neurologic abnormalities [3]. Further, it was reported that elevated maternal thyroid stimulating hormone (TSH) has been associated with an increased risk of pre-term birth, placental abruption, foetal death, and impaired neurological development in the child [4].

Urine iodine concentration (UIC) remains the gold standard in monitoring iodine nutrition at the population 
level [5]. Serum TSH can be used as an indicator of iodine nutrition, because it is determined mainly by the level of circulating thyroid hormone, which in turn reflects iodine intake. However, in older children and adults, although serum TSH may be slightly increased due to iodine deficiency, values often remain within the normal range [3]. As a single hormone determinant, serum TSH provides the most sensitive index to reliably detect thyroid function abnormalities [6]. Therefore, this study was designed to assess the iodine nutrition of pregnant women prospectively during the course of the pregnancy with reference to the urine iodine concentration and the thyroid functions. It was also aimed at evaluating the effectiveness of salt iodization programme in maintaining iodine nutrition among pregnant women in Sri Lanka.

\section{Methods}

This prospective cohort study was conducted in the Galle district in the South of Sri Lanka during the period from July 2012 to September 2014 with approval of the Ethics Review Committee of the Faculty of Medicine, University of Ruhuna, Sri Lanka. The calculated sample size was 385. A possible prevalence of $50 \%$ iodine deficiency among pregnant women was assumed and it was further inflated by $10 \%$ to cover up possible termination of pregnancies and drop outs during the study period. Altogether 425 pregnant women were enrolled in the study. With an informed consent, pregnant women with gestational age: $\leq 12$ weeks (calculated by the date of last menstrual period) were included in the study. Pregnant women with previous history of thyroid and renal diseases were excluded. Data collection was done by using a pretested interviewer administered questionnaire.

An examination of the neck was done to assess the size of the thyroid gland by palpation and by ultrasound (US) scanning at their antenatal clinics using a portable scanner with a high frequency linier 7.5-10 MHz transducer. The volume of the thyroid gland was calculated from the measurements of the depth (d), the width (w), and the length (l) of each lobe by the formula recommended by World Health Organization [7]. The thyroid volume taken was the sum of volumes of both lobes. The volume of the isthmus was not included as the measurement did not include the thyroid capsule (hyper echoic to the gland tissue) or the thyroid isthmus.

Clean mid stream spot urine samples were collected from study subjects at the study entry, at the second (at or around $24^{\text {th }}$ weeks of gestation) and at the third (at or around $36^{\text {th }}$ weeks of gestation) trimesters to iodine free, screw capped plastic containers. Collected urine samples were transported in cold packs to the laboratory and stored at $-80{ }^{\circ} \mathrm{C}$ until the analysis was completed. Urine samples were analyzed in duplicate within a week of collection using ammonium persulfate digestion method [7] at the iodine contamination free laboratory. Blood samples of $5 \mathrm{~mL}$ were drawn from each participant, at the study entry and at the third trimester and serum was separated and stored at $-80{ }^{\circ} \mathrm{C}$ until analysis for thyroid profile (TSH, free thyroxine and thyroglobulin) was done. Thyroid profile was measured using enzyme-linked immunosorbent assay (ELISA) kits provided by MP Biochemicals, USA. The reference values recommended by the American Thyroid association (ATA) for TSH during pregnancy, $0.1-2.5 \mu \mathrm{IU} / \mathrm{mL}$ in the first trimester and $0.3-3.0 \mu \mathrm{IU} / \mathrm{mL}$ in the third trimester [8] were used for comparison.

\section{Statistical methods}

Results of laboratory analysis are presented as mean \pm standard deviation (SD) or median with inter-quartile range (IQR). For variables exhibiting a skewed distribution, the median was used as the measure of central tendency together with the IQR. Wilcoxon signed ranks test was used to compare biochemical parameters at different intervals and linear regression analysis to test for correlations between UIC with other variables. A $p$-value less than 0.05 was considered as significant. Statistical analyses were performed using the SPSS version 16 (SPSS, Chicago, IL).

\section{Results}

The mean age of the 425 pregnant women included in the study was 28.2 years (range $16-44$ years). However, 52 pregnant women were lost on follow up, 22 had early termination of pregnancy; 10 did not attend clinics; 14 moved from the region; 6 refused to attend phlebotomy sessions). Therefore, only 389 and 373 urine samples were analysed in the second trimester and the third trimester respectively. Mean \pm SD height and weight of the study subjects were $154.2 \pm 6.1 \mathrm{~cm}$ and $51.7 \pm 10.1 \mathrm{Kg}$ respectively. The mean BMI of the women at study entry was $22.2 \mathrm{~kg} / \mathrm{m}^{2}$ and $32.4 \%$ of the women were classified as undernourished (BMI $<18.5 \mathrm{~kg} / \mathrm{m}^{2}$ ). Further, 166 $(39.1 \%)$ women were in their first pregnancy. 301 (70.8 \%) were Sinhalese and the rest $(n=124,29.2 \%)$ were Muslims. Even though 322 (75.76 \%) women had completed education up to secondary level, only 104 (24.5\%) were employed and the demographic data of the study sampleis given in Table 1 .

In the assessment of thyroid gland, it was revealed that $67(16.0 \%)$ women had palpable or visible goitres and 55 $(13.1 \%)$ of them had a goitre that was palpable but not visible. The median thyroid volume of the sample was $5.16 \mathrm{~mL}$ (IQR $4.30 ; 6.10 \mathrm{~mL}$ ) as measured by US scanning. The thyroid volume has shown a significant direct relationship with the gland size since the mean \pm SD volume among grade 0 was $5.25 \pm 1.5 \mathrm{ml}$; grade 1 was $5.89 \pm$ $1.6 \mathrm{ml}$ whereas grade 2 was $8.11 \pm 6.1 \mathrm{ml}(t$ test $16.9, p<$ $0.001)$. Further, it was evident that mean thyroid volume 
Table 1 Baseline characteristics of study participants ${ }^{a}$

\begin{tabular}{|c|c|c|}
\hline Characteristics & $n$ & $\%$ \\
\hline \multicolumn{3}{|l|}{ Age in years } \\
\hline $16-25$ & 138 & 32.6 \\
\hline $26-35$ & 242 & 57.0 \\
\hline$\geq 36$ & 45 & 10.4 \\
\hline \multicolumn{3}{|l|}{ Parity } \\
\hline 1 & 166 & 39.1 \\
\hline $2-3$ & 235 & 55.3 \\
\hline$\geq 4$ & 24 & 5.6 \\
\hline \multicolumn{3}{|l|}{ Level of education } \\
\hline Primary \& Secondary & 100 & 23.7 \\
\hline Passed O/L & 148 & 34.3 \\
\hline Passed A/L \& above & 177 & 42.0 \\
\hline \multicolumn{3}{|l|}{ Social class } \\
\hline Class - | \& || & 68 & 16.0 \\
\hline Class - III \& IV & 213 & 50.2 \\
\hline Class - V \& VI & 144 & 33.8 \\
\hline \multicolumn{3}{|l|}{ Thyroid size } \\
\hline Grade 0 & 354 & 84.1 \\
\hline Grade 1 & 55 & 13.1 \\
\hline Grade 2 & 12 & 2.8 \\
\hline
\end{tabular}

$(5.10 \pm 1.9 \mathrm{ml})$ of women who were in their first pregnancy was significantly low ( $t$ test $14.1, p<0.001)$ when compared with that of women who were in their second or subsequent pregnancies (mean volume of $5.61 \pm$ $1.9 \mathrm{ml}$ ). Further, the younger women (age $<25$ years) had significantly lower mean thyroid volume ( $t$ test 5.08, $p=$ 0.04 ) when compared with older group (age $>25.1$ years) of pregnant women $(5.11 \pm 1.4 \mathrm{ml}$ vs. $5.61 \pm 2.3 \mathrm{ml}$ respectively).

The median UIC of women dropped significantly with progression of pregnancy $(p<0.001)$, and the concentrations varied widely at each trimester (Table 2). The median UIC of the women in first trimester was $170.9 \mu \mathrm{g} / \mathrm{L}$ (IQR $100.00-261.10 \mu \mathrm{g} / \mathrm{L}$ ). It was dropped to $123.80 \mu \mathrm{g} / \mathrm{L}$ (IQR $73.50-189.50 \mu \mathrm{g} / \mathrm{L})$ at the second trimester $(\mathrm{Z}=7.28$; $p<$ 0.001). A further drop of UIC at the end of $3^{\text {rd }}$ trimester to $105.00 \mu \mathrm{g} / \mathrm{L}$ (IQR $67.00-153.50 \mu \mathrm{g} / \mathrm{L}$ ) was evident with a statistically significant reduction $(\mathrm{Z}=4.11 ; p<0.001)$. The first trimester urinary iodine level has a significant positive correlation ( $r=0.124, p=0.02)$ with women's weight, but not with any other parameters (demographic \& biochemical) at the study entry.

The serum TSH level of the subjects in their $1^{\text {st }}$ trimester was $1.3 \mu \mathrm{IU} / \mathrm{mL}$ (IQR $0.8-1.8 \mu \mathrm{IU} / \mathrm{mL}$ ). At the end of the $3^{\text {rd }}$ trimester it was significantly increased to $1.6 \mu \mathrm{IU} / \mathrm{mL}$ (IQR 1.2-2.1 $\mu \mathrm{IU} / \mathrm{mL}) \quad$ (Z-test $=6.4, p<$ 0.001). When method specific reference values for pregnancy $(0.3-5.2 \mu \mathrm{IU} / \mathrm{mL})$ is used to determine the prevalence of hypothyroidism, $10(2.4 \%)$ and $2(0.5 \%)$ pregnant women with serum $\mathrm{TSH}>5.2 \mu \mathrm{IU} / \mathrm{mL}$ at the first trimester and third trimester respectively were identified. None of them had serum TSH values below the lower limit of the reference range. As per ATA reference values, $47(11.2 \%)$ subjects in the first trimester and 32 $(8.7 \%)$ at the third trimester were hypothyroid, indicating a higher prevalence. Median vales of $\mathrm{fT}_{4}$ for first and third trimesters were $18.0 \mathrm{pmol} / \mathrm{L}$ and $15.5 \mathrm{pmol} / \mathrm{L}(p=$ 0.002 ) respectively. None of the subjects were found with $\mathrm{fT}_{4}$ values below the lower limit $(<6.4 \mathrm{pmol} / \mathrm{L})$ of the method specific reference (hypothyroid) range in both first and third trimesters. Serum thyroglobulin level was also determined to assess the maternal iodine nutrition among pregnant women at the study entry and the median thyroglobulin level was $5.09 \mu \mathrm{g} / \mathrm{L}$. Of the sample, 47 subjects had thyroglobulin level $<3.0 \mu \mathrm{g} / \mathrm{L}$.

We performed multiple regression analysis with stepwise elimination (forward and backward) to assess the effect of selected explanatory variables on the urinary iodine levels at first and third trimester respectively (Table 3). After controlling for other independent variables (anthropometry, demographic and biochemical parameters), only weight was found to have statistically significant correlations with the first trimester urinary iodine level. However, initial body mass index (BMI), goitre size, thyroid volume and parity had significant correlations with the third trimester urinary iodine levels. Furthermore, thyroid volume accounted for $4.5 \%$ of the urinary iodine variation $\left(r^{2}=0.045\right)$.

\section{Discussion}

The present study shows that the iodine level of pregnant women in Galle, Sri Lanka was adequate at the onset of pregnancy where as there were only $4.3 \%$ pregnant women with moderate iodine deficiency (urinary iodine $<50.0 \mu \mathrm{g} / \mathrm{L}$ ). However, with the progression of pregnancy there was steady decline in maternal urinary iodine status and increase in deficiency status and the observed difference was highly significant $(p<0.001)$. Such progressive decline in urine iodine level with the advancement of gestational age was quite compatible with the results of studies done in Bangladesh [9], Congo [10], Nigeria [11] and in some other countries too $[12-14]$. This reduction in UI concentration can be attributed to the miss-match between the increased demand and the supply of iodine with the advancement of the pregnancy [15]. A recent study done in France showed that median urine iodine level in the first trimester of the pregnancy was low $(116.0 \mu \mathrm{g} / \mathrm{L})$ [4] and similar finding was reported from Thailand (median UI level of $108.0 \mu \mathrm{g} / \mathrm{L}$ in $1^{\text {st }}$ trimester pregnant women) too [16]. It was evident that even in iodine-sufficient 
Table 2 Biochemical parameters during pregnancy ${ }^{a}$

\begin{tabular}{|c|c|c|c|}
\hline & First trimester & Second trimester & Third trimester \\
\hline$n$ & 425 & 389 & 373 \\
\hline Weeks (weeks) & $9.5 \pm 1.8$ & $25.3 \pm 1.4$ & $36.6 \pm 0.6$ \\
\hline \multicolumn{4}{|l|}{ Urinary iodine ( $\mu \mathrm{g} / \mathrm{L})$} \\
\hline Median & 170.90 & 123.80 & 105.00 \\
\hline $25^{\text {th }}-75^{\text {th }}$ percentiles & $100.00-261.10$ & $73.50-189.50$ & $67.00-153.50$ \\
\hline $10^{\text {th }}-90^{\text {th }}$ percentiles & $68.40-329.70$ & $46.00-250.30$ & $49.20-218.80$ \\
\hline Total range & $6.30-491.70$ & $5.80-466.70$ & $16.20-505.50$ \\
\hline $\mathrm{n}(\%)<50 \mu \mathrm{g} / \mathrm{L}^{\mathrm{b}}$ & $18(4.3)$ & $36(9.6)$ & $40(10.8)$ \\
\hline $\mathrm{n}(\%)<150 \mu \mathrm{g} / \mathrm{L}^{\mathrm{b}}$ & $159(37.4)$ & $168(45.0)$ & $232(62.2)$ \\
\hline $\mathrm{n}(\%)>250 \mu \mathrm{g} / \mathrm{L}^{\mathrm{b}}$ & $124(29.1)$ & $37(10.7)$ & $26(6.9)$ \\
\hline \multicolumn{4}{|l|}{ Serum TSH ( $\mu \mathrm{IU} / \mathrm{mL})$} \\
\hline Median & 1.30 & & 1.60 \\
\hline $25^{\text {th }}-75^{\text {th }}$ percentiles & $0.80-1.90$ & & $1.20-2.10$ \\
\hline $10^{\text {th }}-90^{\text {th }}$ percentiles & $0.50-2.50$ & & $0.80-2.98$ \\
\hline Total range & $0.40-16.60$ & & $0.50-11.60$ \\
\hline \multicolumn{4}{|l|}{ Serum $\mathrm{fT}_{4}(\mathrm{pmol} / \mathrm{L})$} \\
\hline Median & 18.00 & & 15.45 \\
\hline $25^{\text {th }}-75^{\text {th }}$ percentiles & $15.45-23.20$ & & $11.60-21.80$ \\
\hline $10^{\text {th }}-90^{\text {th }}$ percentiles & $10.60-28.30$ & & $10.30-28.30$ \\
\hline Total range & $10.30-42.50$ & & $10.30-39.90$ \\
\hline \multicolumn{4}{|l|}{ Serum Thyroglobulin ( $\mu \mathrm{g} / \mathrm{L})$} \\
\hline Median & 5.09 & & \\
\hline $25^{\text {th }}-75^{\text {th }}$ percentiles & $1.97-7.37$ & & \\
\hline $10^{\text {th }}-90^{\text {th }}$ percentiles & $0.38-15.65$ & & \\
\hline Total range & $0.14-42.0$ & & \\
\hline
\end{tabular}

aurinary iodine levels was assessed at each trimester, except for serum thyroglobulin other biochemical parameters were assessed at the study entry (first trimester) and towards the end of third trimester

bWorld Health Organization's criteria for assessing iodine status on population basis: for pregnant women moderate iodine deficiency $<50 \mu \mathrm{g} / \mathrm{L}$ insufficient intake $<150 \mu \mathrm{g} / \mathrm{L}$ and above requirement $>250 \mu \mathrm{g} / \mathrm{L}$

countries pregnant women may be at risk of mild deficiency; because of the major physiological changes in thyroid function occurring during pregnancy leading to increased loss of iodine and the need of much higher iodine supply [17].

In contrast, results of national health and nutrition examination survey in USA showed that UI levels were increased in the second and third trimesters when compared to the first trimester [18]. This increase in iodine status was attributed to the usage of supplements containing iodine during pregnancy. However, Sri Lanka did not prescribe supplements containing iodine during pregnancy as a part of their antenatal management. Further, a recent study done in India showed that mean UI levels above normal in all trimesters, with a peak in mid-pregnancy with no inter-trimester variation and only a very few (2\%) had iodine deficiency [19].

An assessment of thyroid functions concurrently with urinary iodine level would give a clear picture on maternal iodine nutrition. Thyroid dysfunction during pregnancy was classified from subclinical hypothyroidism $(\mathrm{SCH})$ to overt hypothyroidism $(\mathrm{OH})$. The $\mathrm{SCH}$ was defined as having serum TSH level in the range of $2.5-10.0 \mu \mathrm{IU} / \mathrm{mL}$ with a normal $\mathrm{fT}_{4}$ concentration. The distinction of $\mathrm{OH}$ from $\mathrm{SCH}$ was important because around $2.0-2.5 \%$ of healthy non pregnant women in United States were considered as having $\mathrm{SCH}$, but it would be anticipated that such percentages would be higher in areas of iodine insufficiency [8]. Since the $\mathrm{SCH}$ is a biochemical diagnosis, the symptoms may be mild, non-specific and may mimic typical symptoms in pregnancy. The increase in serum TSH level with the advancement of pregnancy in our study was compatible with the findings of the study done in Bangladesh [9]. A recent study done on pregnant women (in their second trimester) in Iran showed that the prevalence of hypothyroidism in pregnant woman was $13.7 \%$ and the prevalence of hyperthyroidism was $1.5 \%$ [20]. Further, Yassaee et al., [21] in 2014 reported $4.15 \%$ prevalence of $\mathrm{SCH}$ in the same country. The prevalence of 
Table 3 Multiple regression equation with urinary iodine levels at each trimester as the dependent variables and selected independent variables among study subjects ${ }^{a}$

\begin{tabular}{|c|c|c|c|c|}
\hline \multirow[t]{2}{*}{ Variable } & \multicolumn{2}{|c|}{ Urinary iodine $\left(T_{1}\right)$} & \multicolumn{2}{|c|}{ Urinary iodine $\left(T_{3}\right)$} \\
\hline & $\bar{B}$ & $p$-value & $\bar{B}$ & $p$-value \\
\hline \multicolumn{5}{|l|}{ Anthropometry } \\
\hline Weight & 0.157 & 0.006 & 0.090 & 0.37 \\
\hline Height & -0.033 & 0.56 & 0.032 & 0.60 \\
\hline $\mathrm{BMI}$ & 0.005 & 0.96 & 0.167 & 0.005 \\
\hline Thyroid volume & -0.031 & 0.60 & 0.117 & 0.03 \\
\hline Thyroid size & -0.081 & 0.15 & 0.136 & 0.02 \\
\hline \multicolumn{5}{|l|}{ Demography } \\
\hline Social class & 0.074 & 0.20 & -0.010 & 0.87 \\
\hline Education level & 0.019 & 0.73 & -0.008 & 0.90 \\
\hline Parity & 0.062 & 0.28 & -0.123 & 0.04 \\
\hline Age in years & -0.002 & 0.97 & -0.009 & 0.89 \\
\hline Period of gestation & -0.082 & 0.15 & 0.044 & 0.45 \\
\hline \multicolumn{5}{|l|}{ Biochemical analysis } \\
\hline Serum TSH ${ }^{b}$ & -0.066 & 0.25 & -0.006 & 0.92 \\
\hline Serum $\mathrm{fT}_{4}^{\mathrm{b}}$ & 0.040 & 0.49 & -0.061 & 0.29 \\
\hline Serum thyroglobulin ${ }^{c}$ & -0.045 & 0.62 & -0.069 & 0.51 \\
\hline$p$ (model) & 0.006 & & $<0.001$ & \\
\hline$r^{2}$ & 0.025 & & 0.045 & \\
\hline
\end{tabular}

${ }^{a}$ Anthropometry and demographic data were collected at study entry (first trimester) were compared with urinary iodine level of first and third trimester ${ }^{\mathrm{b}}$ These biochemical parameters were assessed separately first trimester data with first trimester urinary iodine and third trimester data with third trimester urinary iodine respectively

'Serum thyroglobulin level was measured at study entry and compared with urinary iodine level of first and third trimester

hypothyroidism among north Indian pregnant women was14.3\% during the first trimester [22].

Sri Lanka was categorized as a country with satisfactory iodine nutrition status and the coverage of adequate iodized salt usage was $>90 \%$ [23]. Further, Sri Lanka was considered as having achieved all the criteria of WHO/ ICCIDD for monitoring progress towards sustainable elimination of IDD. However, no national level studies have been conducted to assess the iodine nutrition in pregnant women in Sri Lanka up to 2010, when a study revealed that the overall median urine iodine concentration among pregnant women was $113.7 \mu \mathrm{g} / \mathrm{L}$ indicating an iodine deficiency in Sri Lankan pregnant women [24]. This cross sectional study showed that pregnant women who were in the second and third trimesters had lower UI level than first trimester pregnant women. To our knowledge, present study is the first prospective study done in Sri Lanka to assess the gestational changes in iodine nutrition along with the thyroid profile assessment.

In this group of pregnant women, UI level was significantly reduced over the period of gestation and almost three fourth of the pregnant women were iodine deficient $(<150.0 \mu \mathrm{g} / \mathrm{L})$ towards the end of the pregnancy. However, this iodine deficiency status was apparently not reflected by the serum TSH level. Even though iodine deficiency was a significant problem in this sample, prevalence of severe iodine deficiency $(<50.0 \mu \mathrm{g} / \mathrm{L})$ was very low. Results of the present study confirmed that pregnant women in this study population were having mild iodine deficiency with normal TSH level. Maintaining median serum TSH level within the reference range (increased serum TSH values remained within the normal range) with progressive increase in iodine deficiency in this study sample may be explained by this mild iodine deficiency status and the foetuses of mothers who are apparently euthyroid may have insufficient $T_{4}$ for its normal neurodevelopment [25]. These conditions have been found to be related to mild and subclinical cognitive and psychomotor deficits in neonates, infants and children [17] and it highlights the importance of maintaining proper iodine nutrition throughout the pregnancy to ensure optimal maternal thyroid function for a better pregnancy outcome.

This study has some important points. The design was suited to evaluate changes in iodine nutrition during the course of the pregnancy because we measured the urine iodine excretion in each trimester in the same study subject whereas many of the other studies were done in cross- sectional manner [18, 24, 26, 27]. Pregnant women of the study sample were not given iodine supplements and it mainly explores the effectiveness of iodized salt, diet and water as sources of iodine during pregnancy. The main limitations were the lack of information concerning iodine concentrations in edible salts utilized at each household and recruitment of pregnant women from a health division close to the main city of the Southern province where there may be a difference in level of education, nutritional status and social class compared to the general population of the country. Therefore the results may not be generalized to the Sri Lankan pregnant population. It would have been useful to have a non-pregnant control group from the same area to ascertain whether lower UI concentrations during pregnancy could be attributed to pregnancy itself or to different dietary choices among them.

\section{Conclusions}

In conclusion, pregnant women in Galle, Sri Lanka have generally inadequate urinary iodine excretion during progression of the pregnancy. They should be encouraged to either consume iodine-rich food or to take appropriate multiple micronutrient capsules including iodine to improve their iodine status during pregnancy. However, existing iodine supplement through salt iodization programme should be continued and monitored strictly with a close surveillance to maintain a satisfactory iodine status in the 
pregnant women. Further studies are needed to clarify the potential impact of the women's consistently low or excessive iodine intake and benefits or adverse effects of iodine supplementation on the health of their developing offspring.

\section{Abbreviations}

ATA: American thyroid association; BMI: Body mass index; ELISA: Enzyme-linked immunosorbent assay; IDD: lodine deficiency disorders; IQR: Interquartile range; $\mathrm{OH}$ : Overt hypothyroidism; SCH: Subclinical hypothyroidism; SD: Standard deviation; TSH: Thyroid stimulating hormone; UI: Urinary iodine; UIC: Urine iodine concentration; US: Ultra sound

\section{Acknowledgements}

We would like to thank officials in Galle Regional Health Services and the public health midwives who assisted in subject recruitment and follow up. The technical staff of the Nuclear Medicine Unit and Department of Biochemistry for sample analysis and the study participants for their tolerance is also appreciated.

\section{Funding}

The University Grants Commission of Sri Lanka and the project of Transforming University of Ruhuna into international level (TURIS) provided the financial assistance.

\section{Availability of data and materials}

The written consent was obtained only to publish group data from each participant at the enrolment to the study. This study was conducted as the requirement for the postgraduate degree of the first author. Raw data cannot be deposited in publicly available repositories since consent was not obtained as well as the rules and regulations of the Faculty of Graduate Studies of University of Ruhuna, Sri Lanka.

\section{Authors' contributions}

EDZ, MH and CL contributed the idea in the study. EDZ was involved in data collection in the field. Data entry was done by EDZ while sample analysis was done by EDZ and $\mathrm{MH}$. Data analysis was done by EDZ and $\mathrm{MH}$. EDZ was guided by $\mathrm{MH}$ and $\mathrm{CL}$ in creating the first draft. All authors read and approved the final manuscript.

\section{Authors' information}

EDZ is a junior academic attached to Faculty of Medicine, University of Ruhuna, Sri Lanka. MH and $\mathrm{CL}$ are serving in the same institute and supervise this research study.

\section{Competing interests}

The authors declare that they have no competing interests.

\section{Consent for publication}

Not applicable.

\section{Ethics approval and consent to participate}

The study received approval from the Ethics Review Committee of the Faculty of Medicine, University of Ruhuna, Sri Lanka.

\section{Author details}

'Department of Biochemistry, Faculty of Medicine, University of Ruhuna, Galle, Sri Lanka. ${ }^{2}$ Nuclear Medicine Unit, Faculty of Medicine, University of Ruhuna, P.O. Box 70, Galle, Sri Lanka. ${ }^{3}$ Department of Community Medicine, Faculty of Medicine, University of Ruhuna, Galle, Sri Lanka.

\section{Received: 8 October 2015 Accepted: 4 October 2016}

Published online: 12 October 2016

\section{References}

1. Smyth PPA, O'Herlihy C. Dietary iodine intake in pregnancy. Ir Med J. 2006; 99(4):103.

2. Becks GP, Burrow GN. Thyroid disorders and pregnancy. Ontario: Thyroid Foundation of Canada; 2000.

3. Zimmermann MB. lodine deficiency in pregnancy and the effects of maternal iodine supplementation on the offspring: a review. Am J Clin Nutr. 2009:89(S): $6685-72$.
4. Allan WC, Haddow JE, Palomaki GE, Williams JR, Mitchell ML, Hermos RJ, Faix JD, Klein RZ. Maternal thyroid deficiency and pregnancy complications: implications for population screening. J Med Screen. 2000;7:127-30.

5. Brucker-Davis F, Ferrari P, Gal J, Berthier F, Fenichel P, Hieronimus S. lodine status has no impact on thyroid function in early healthy pregnancy. J Thyroid Res. 2012; Article ID 168764. https://www.ncbi.nlm.nih.gov/pmc/ articles/PMC3515943/pdf/JTR2012-168764.pdf.

6. Glinoer D, Spencer CA. Serum TSH determinations in pregnancy: how, when and why? Nat Rev Endocrinol. 2010;6(9):526-9.

7. WHO. Assessment of iodine deficiency disorders and monitoring their elimination: a guide for programme managers. Geneva: WHO; 2007.

8. Stagnaro-Green A, Abalovich M, Alexander E, Azizi F, Mestman J, Negro R. Guidelines of the American thyroid association for the diagnosis and management of thyroid disease during pregnancy and postpartum. Thyroid. 2011;21(10):1081-125.

9. Medhi T, Hoquei M, Nasreen ZA, Shirin F, Hakimkhan M. Maternal iodine status and thyroid function during pregnancy. J Med. 2009;10:56-9.

10. Habimana L, Twite KE, Wallemacq P, Nayer PD, Daumerie C, Donnen P, et al. lodine and iron status of pregnant women in Lubumbashi, Democratic Republic of Congo. Public Health Nutr. 2013;16(8):1362-70.

11. Ujowundu CO, Ukoha Al, Agha CN, Nwachukwu N, lgwe KO. Assessment of current iodine status of pregnant women in a suburban area of Imo State Nigeria, twelve years after universal salt iodization. Afr J Biochem Res. 2010:4(1):6-12

12. Eltom A, Eltom M, Elnagor B, Elbagir M, Gebre-Medhim M. Changes in lodine metabolism during late pregnancy and lactation: a longitudinal study among Sudanese women. Eur J Clin Nutr. 2000;54(5):429-33.

13. Azizi F, Aminorryo A, Hedayatin M, Rezvanian $H$, Amini M, Mirmiran $P$. Urinary lodine excretion in pregnant women residing in areas with adequate iodine intake. Public Health Nutr. 2002;6:95-8.

14. Pathak P, Singh P, Kapil U, Reghuvanshi RA. Prevalence of iron, vit-A and iodine deficiency amongst adolescent pregnant mothers. Indian J Pediatr. 2003:70:299-301.

15. Lazarus J. In: De Groot $\sqcup$, Beck-Peccoz P, Chrousos G, editors. Endotext [internet]. South Dartmouth: MDText.com, Inc; 2000 [accessed 10 $0^{\text {th }}$ February 2015].

16. Gowachirapant S, Winichagoon P, Wyss L, Tong B, Baumgartner J, MelseBoonstra A, Zimmermann MB. Urinary iodine concentrations indicate iodine deficiency in pregnant thai women but iodine sufficiency in their schoolaged children. J Nutr. 2009:139(6):1169-72.

17. Trumpffa C, De-Schepper J, Tafforeau J, Van Oyen H, Vanderfaeillie J, Vandevijvere S. Mild iodine deficiency in pregnancy in Europe and its consequences for cognitive and psychomotor development of children: a review. J Trace Elem Med Biol. 2013;27(3):174-83.

18. Caldwell KL, Pan Y, Mortensen ME, Makhmudov A, Merrill L, Moye J. lodine status in pregnant women in the national children's study and in U.S. women (15-44 Years), National Health and Nutrition Examination Survey 2005-2010. Thyroid. 2013;23(8):927-37.

19. Grewal E, Khadgawat R, Gupta N. Assessment of iodine nutrition in pregnant north Indian subjects in three trimesters. Indian J Endocrinol Metab. 2013:17(2):289-93.

20. Saki F, Dabbaghmanesh MH, Ghaemi SZ, Forouhari S, Omrani GR, Marzieh BM. Thyroid function in pregnancy and its influences on maternal and foetal outcomes. Indian J Endocrinol Metab. 2014;12(4):78-93.

21. Yassaee F, Farahani M, Abadi AR. Prevalence of subclinical hypothyroidism in pregnant women in Tehran-Iran. Int J Fertil Steril. 2014;8(2):163-6.

22. Dhanwal DK, Prasad S, Agarwal AK, Dixit V, Banerjee AK. High prevalence of subclinical hypothyroidism during first trimester of pregnancy in North India. Indian J Endocrinol Metab. 2013;17(4):281-4.

23. Jayatissa R, Gunathilake MM, Fernando DN. lodine nutrition status among schoolchildren after salt iodization. Ceylon Med J. 2005;4(50):144-8.

24. Jayatissa R, Gunathilaka MM, Ranbanda JM, Peiris P, Jayasingha J, Ekanayaka $\mathrm{P}$, Kulathunga $\mathrm{H}$. lodine status of pregnant women in Sri Lanka. Sri Lanka J Diab Endocrinol Metabol. 2013;3:4-7.

25. Melse-Boonstra A, Nidhi J. lodine deficiency in pregnancy, infancy and childhood and its consequences for brain development. Clin Endocrinol Metab. 2010:24:29-38.

26. Silva KDR, Munasinghe LD. Urinary iodine concentration of pregnant women and female adolescents as an indicator of excessive iodine intake in Sri Lanka. Food Nutr Bull. 2006;1(27):12-8.

27. Kedir H, Berhane Y, Worku A. Subclinical iodine deficiency among pregnant women in Haramaya district, eastern Ethiopia: A community-based study. J Nutr Metab. 2014; Article ID 878926. https://www.hindawi.com/journals/ jnme/2014/878926/ 